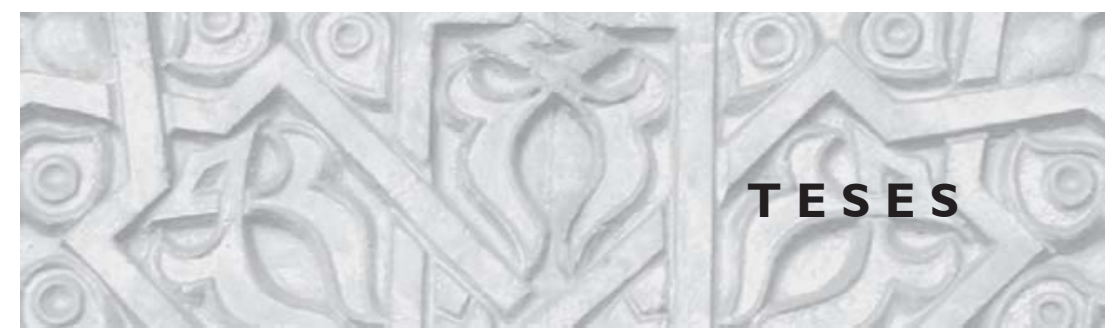

\section{A primeira década da aids no Brasil: o Fantástico apresenta a doença ao público (1983-1992)}

\author{
Germana Fernandes Barata \\ Dissertação de mestrado em História Social, \\ Faculdade de Filosofia, Letras e Ciências Humanas, \\ Universidade de São Paulo,São Paulo, 2006. \\ Rua Tiburcio Cavalcante, 1490/102 Aldeota \\ 60125-100 Fortaleza - CE - Brasil \\ germanabarata@yahoo.com
}

Analisa a divulgação da síndrome da imunodeficiência adquirida (aids), considerada a maior epidemia do século $X X$, pelo programa Fantástico, da Rede Globo de Televisão, entre 1983 e 1992, primeira década em que a doença apareceu na mídia brasileira. No caso da aids, a televisão, principal fonte de informação da população, desempenhou papel-chave ao apresentá-la ao público muito antes que os governos, profissionais da saúde e pesquisadores tivessem respostas seguras sobre a doença. Das 105 notícias divulgadas no programa durante a década, selecionaram-se aquelas (26) que priorizaram os aspectos científicos da enfermidade - encontros científicos, descobertas e avanços na prevenção, diagnóstico e tratamento. Por ser desconhecida, mortal e transmissível sobretudo sexualmente, a aids encontrou espaço reservado no Fantástico, que valoriza histórias extraordinárias, bizarras e grotescas, inspiradas no gênero fait divers. Trabalhos que abordaram a televisão como meio de divulgação da aids são escassos e lidam apenas com campanhas de prevenção da doença. O programa foi pioneiro na divulgação do nome aids na grande mídia ao exibir, em 27 de março de 1983, uma matéria que já trazia a dimensão de 'epidemia do século'. A cobertura priorizou o cenário nacional e o discurso científico, reservando bom espaço para a divulgação da doença e contribuindo para informar a população sobre os meios de prevenção, os avanços científicos em relação à enfermidade e à qualidade do sistema de saúde pública brasileiro. No entanto fica claro também o reforço a mitos e metáforas relativos à história das doenças e à ciência, além dos preconceitos e estigmas contra seus pacientes, sobretudo os pertencentes aos chamados grupos de risco, o que pode ter contribuído para distanciar o telespectador da realidade da doença. A mídia, cuja relação de divulgação com a ciência é tantas vezes problemática, no caso do programa Fantástico preencheu algumas lacunas junto ao grande público, mas deixou a descoberto os flancos por onde interferem questões bioéticas, morais e, afinal, ideológicas. sexualmente

\section{Recriando vínculos familiares: jovens e relações intergeracionais na contemporaneidade}

\section{Carolina de Campos Borges}

Dissertação de mestrado, Programa de Estudos Interdisciplinares de Comunidades e Ecologia Social do Instituto de Psicologia/Universidade Federal do

Rio de Janeiro, Rio de Janeiro, 2006. Rua Fernando Osório 02/12 22230-040 Rio de Janeiro - RJ - Brasil carolinacambor@yahoo.com.br

Trata do estudo das relações intergeracionais na família contemporânea a partir do discurso de jovens. Uma cultura se processa nesse movimento de renovação das gerações, que ocorre por meio de nascimentos e mortes de pessoas. A sociabilidade intergeracional é fundamental para a constituição de uma cultura, pois é através delas que certos valores e práticas são transmitidos aos mais jovens. Nos contextos marcados por processos de mudanças socioculturais acelerados, verificase a exacerbação das diferenças intergeracionais. No caso do contexto histórico contemporâneo, além da intensificação das mudanças socioculturais acentuam-se os valores individualistas e igualitários, o que vem 
transformando as formas de integração entre as gerações. Para melhor entender as formas contemporâneas de constituição do vínculo intergeracional, foram realizadas entrevistas semi-estruturadas com seis jovens (três moças e três rapazes), com idades entre 15 e 20 anos, pertencentes a estratos sociais privilegiados e moradores, com suas famílias, de bairros da Zona Sul da cidade do Rio de Janeiro, onde o fácil acesso aos meios de comunicação e aos bens de consumo propicia o convívio com um universo cultural diversificado e conectado a novos discursos sociais. Todas as entrevistas foram gravadas e transcritas na íntegra.A análise de discurso das transcrições das entrevistas confirmou nossa idéia inicial de que as mudanças socioculturais contemporâneas têm implicações profundas nas relações intergeracionais. Os resultados apontaram ainda para a influência de valores individualistas nas visões dos jovens acerca das relações familiares, das gerações mais velhas e do processo de envelhecimento. Os jovens consideram as diferenças intergeracionais como um elemento distanciador em relação aos seus pais e avós, porque criam dificuldades para o entendimento mútuo. Apesar disso, pode-se observar em seus discursos estratégias de superação das diferenças e de aproximação dos mais velhos, projetando em seus ideais de velhice os atributos da juventude e admirando aqueles adultos que se deixam influenciar pelo estilo de vida dos jovens. Podemos entender que é dessa forma que os jovens estão construindo os laços que os unem às outras gerações. Considerando que todas as gerações que vivem hoje são contemporâneas nos processos de transformação das famílias e das relações intergeracionais, é um desafio de todas as idades encontrar o seu modo de viver, seja na juventude, na idade adulta, na maturidade ou na velhice. Rompendo com as formas tradicionais de integração social, os jovens parecem respeitar as tentativas dos mais velhos de se reinventarem e de absorverem as influências da cultura jovem e apresentam, com primazia, uma abertura à recriação dos vínculos entre as diferentes gerações na contemporaneidade.

\section{Percepção sobre qualidade de vida entre crianças de 4 a 6 anos: educação (física) em saúde na escola}

\author{
Heraldo Simões Ferreira \\ Dissertação de mestrado em Educação em \\ Saúde, Universidade Federal de Fortaleza, \\ Fortaleza, 2005.
}

A qualidade de vida foi muito estudada nas últimas décadas, mas ela pouco tem sido pesquisada a partir da ótica de crianças. A escola, com a disciplina de educação física, procura encontrar meios de promover a saúde e, dessa forma, oferecer uma boa qualidade de vida aos alunos. A saúde não é vista como ausência de doenças, mas sim como um completo bem-estar físico e mental. Por meio da prática de atividades lúdicas durante as aulas de educação física, espera-se a formação de hábitos saudáveis e, em conseqüência, a busca pela qualidade de vida. $\mathrm{O}$ estudo teve como objetivo compreender de que forma as crianças de uma escola pública de Fortaleza percebem a qualidade de vida, os fatores que consideram necessários para isso e em que ordem de importância esses referenciais devem estar dispostos. Trata-se de uma abordagem quantitativo-qualitativa, do tipo descritivo, desenvolvida na Escola de Aplicação Yolanda Queiroz, situada na comunidade do Dendê, incluindo 60 alunos de quatro a seis anos de idade. Para a coleta de dados utilizamos técnicas projetivas - como desenhos e figuras - e o questionário AUQEI. A partir das categorias de qualidade de vida propostas por Sabeh e Verdugo (2002), fizemos uma triangulação metodológica entre os resultados obtidos nas três fases do estudo. Como resultado dessa investigação, percebemos que as crianças envolvidas se preocupam, em ordem de importância, com o brincar (categoria de ócio e atividades recreativas); com a afetividade dos pais (relações interpessoais); e com a moradia (bem-estar material). Concluímos, portanto, que a atividade lúdica é o principal elemento para a aquisição da qualidade de vida infantil dos envolvidos. Recomendamos que somente por meio da reflexão sobre 
a importância do brincar, do jogar e da atividade lúdica na escola, bem como da presença significativa dos pais no ambiente escolar e de ações de educação em saúde para a melhoria das condições de moradia, é que estaremos promovendo a saúde das crianças envolvidas. Esperamos que as idéias deste estudo possam servir de análise para novas pesquisas no ambiente da comunidade do Dendê e que novas políticas públicas de saúde levem em consideração a percepção infantil sobre a qualidade de vida.

\section{A política de 'saúde da população negra' no Brasil: o caso da anemia falciforme (1996-2004)}

\author{
Luciana de Oliveira Macedo \\ Dissertação de mestrado em História das \\ Ciências/Casa de Oswaldo Cruz/Fiocruz, Rio de \\ Janeiro, 2006.
}

Aborda o processo de constituição e desenvolvimento de um campo denominado 'saúde da população negra' no período que se estende de 1996 a 2004. Com o interesse em discutir a construção dessa agenda política na esfera da saúde, o trabalho empreende uma reflexão das ações promovidas pelo Estado no que diz respeito à definição de políticas voltadas para a anemia falciforme, encarada como uma doença de maior prevalência na população negra. Diante dessa questão, o trabalho tem como objetivo identificar como o processo de construção de uma política específica dirigida à população negra interage com um sistema de saúde pública alicerçado nos princípios da universalidade, integralidade e igualdade, conforme prevê o Sistema Único de Saúde (SUS). A dissertação busca também investigar como a caracterização da anemia falciforme como uma 'doença racial' tem sido mobilizada em defesa da formação e legitimação da 'saúde da população negra', mostrando que as interfaces entre 'raça' e 'doença' tornaram-se, nos últimos anos, objeto de políticas públicas. Sendo assim, acredito que a realização de um programa voltado para a anemia falciforme legitima a denominada 'saúde da população negra'. Ela é o resultado de um contexto político-social, no qual a militância negra, instituições intergovernamentais, organizações não governamentais e eventos internacionais e nacionais têm conseguido fazer com que o Estado tenha como foco a 'raça negra', definindo programas fundamentados numa doença específica de natureza genética afeita alegadamente aos 'negros' e objeto de políticas.

\section{Lições da botânica: um ensaio para as aulas de ciências \\ Simone Rocha Salomão \\ Tese de doutorado em Educação, Centro de Estudos Sociais Aplicados/Universidade Federal Fluminense, Niterói, 2005. Rua Nascimento Silva, 250 / apto 501 22421-020 Rio de Janeiro - RJ - Brasil simonesalomao@uol.com.br}

O presente trabalho procura investigar e compreender as aproximações entre ciência e literatura e entre linguagem científica e linguagem literária, suas relações com o ensino e a aprendizagem em ciências e o possível papel potencializador do texto literário na aprendizagem de conteúdos científicos no ensino fundamental. Para tanto, utiliza como fio condutor da pesquisa a peça teatral Lição de botânica, de Machado de Assis, com base na qual são geradas questões para a discussão teórica e caminhos para a pesquisa empírica. Tal pesquisa, implementada com turmas de $6^{\text {a }}$ série de uma escola pública de Macaé (RJ), constituiu-se da apresentação de uma montagem dessa peça aos alunos, discussão junto a eles sobre o texto, atividades escritas e montagem de um herbário. As atividades escritas, realizadas antes e após a apresentação da peça, incluíram questionários de perguntas abertas e exercícios, que solicitaram dos alunos reflexão e análise sobre a peça teatral, em particular sobre aspectos relacionados com a botânica e sua linguagem, e, ainda, sobre a própria atividade científica. Entre as referências teóricas mobilizadas, destacam-se 
as considerações do Círculo de Bakhtin sobre linguagem, sobretudo as noções de exotopia e plurilingüismo. As reflexões desenvolvidas são traçadas através de dois eixos - 'ciência e literatura' e 'linguagem e aprendizagem' - envolvendo aspectos relativos às diferentes linguagens, à história da biologia e da botânica e à produção de linguagem e de significados pelos alunos, inserida em sua dinâmica de aprendizagem.

\section{A promoção da saúde na educação infantil}

Fernanda Denardin Gonçalves

Dissertação de mestrado em Educação em Saúde, Universidade de Fortaleza, Fortaleza, 2006. fdenardi@puc.cl

A escola como espaço educativo vem sendo instigada a ultrapassar uma prática meramente cognitivista para tornar-se um novo foco de atuação, preocupado com a formação do indivíduo como um todo e transformado num dos espaços ideais para a promoção da saúde. A escola de educação infantil, que com o passar dos anos vem adquirindo mais respaldo, até mesmo graças à nova lei (LDB 9.394/96), vem se caracterizando como um nível de ensino de importância fundamental, já que as crianças de até seis anos podem e devem ser trabalhadas para a formação de hábitos saudáveis e a busca pela qualidade de vida.

Este estudo teve como objetivo avaliar as ações educativas em saúde desenvolvidas por uma escola de educação infantil em Fortaleza (CE), identificando as práticas de saúde realizadas e como se dá ali o trabalho de promoção de saúde. Trata-se de estudo des- critivo, de abordagem qualitativa, desenvolvido na Creche Escola Felisbela Benvinda Guimarães. Como técnica de coleta de dados utilizou-se a análise documental, a observação direta e a entrevista semi-estruturada. A partir do referencial teórico proposto por Kolbe (1996) e McBriude (1999), pela Organização Mundial de Saúde, pela Rede Européia de Projetos de Escolas Promotoras de Saúde, pelos Ministérios da Educação e da Saúde, através dos Parâmetros Curriculares Nacionais (1997), e pela Rede Nacional de Escolas Promotoras de Saúde, construíram-se diretrizes norteadoras para o desenvolvimento da proposta de escola promotora de saúde. Utilizando esse material como roteiro de trabalho, os dados foram coletados e analisados tomando como referência a análise de conteúdo defendida por Bardin (1997). Nesse processo, cinco categorias temáticas emergiram das falas dos entrevistados: (1) promoção da saúde na prática pedagógica; (2) construção de um ambiente interno saudável; (3) atuação da equipe de saúde em relação aos professores; (4) orientação da família a partir da intervenção da escola; e (5) atendimento aos alunos. Como resultado do estudo identificaram-se as práticas de promoção da saúde no espaço da educação infantil, discutindo prioritariamente como elas se desenvolvem no âmbito escolar. Identificou-se, também, a necessidade de um trabalho sistemático de formação dos profissionais que exercem tais atividades, para que a partir de conversas, trocas de experiências e diálogos entre os educadores seja possível avaliar as práticas e buscar fundamentos teóricos para embasá-las. Concluiu-se que somente a partir da reflexão sobre a ação educativa desenvolvida pelos educadores será possível afirmar: “Eu promovo a saúde dentro do meu espaço escolar! Eu sou um educador em saúde!" 